УДК 636.598 .03

(C) 2017

Суханова С. Ф., доктор сельскохозяйственных наук, профессор,

Азаубаева Г. С., доктор сельскохозяйственных наук, доцент

ФГБОУ ВО «Курганская государственная сельскохозяйственная академия имени Т. С. Мальцева», г. Курган, Россия

\title{
ПРОДУКТИВНОСТЬ ГУСЕЙ РОДИТЕЛЬСКОГО СТАДА ПРИ ИСПОЛЬЗОВАНИИ КОРМОВОЙ ДОБАВКИ «ВЕТОСЕЛ Е ФОРТЕ»
}

\section{Рецензент - доктор сельскохозяйственных наук А. Г. Махалов}

Исследованиями установлено, что использование кормовой добавки «Ветосел Е форте» для гусей родительского стада в оптимальной дозировке 0,6 мл/10 л питьевой воды позволило увеличить яичную продуктивность на 2,15-10,40\%, сохранность на 0,47-1,68\%, оплодотворенность яиц - на 0,993,09\%, выводимость - на 5,81-11,02, вывод молодняка - на 6,10-12,66\%. При ее использовании отмечено более выраженное тканевое дыхание, фагоиитарная активность, число и индекс увеличились на 4,34\%, $10,28(P \leq 0,05)$ и 2,82\%. Суточные гусята, полученные от подопытных гусынь отличались более высоким неспецифическим иммунитетом. За счет использования «Ветосел Е форте» расход корма на 1000 шт. яиц уменьшился на 2,26-12,84\%, а уровень рентабельности производства инкубационных гусиных яиц увеличился - на 1,98-4,74\%.

Ключевые слова: кормовая добавка «Ветосел E форте», гуси, яичная продуктивность, показатели инкубации, неспецифический иммунитет, расход корма, рентабельность.

Постановка проблемы. Известно, что птицеводство - одна из наиболее интенсивных, динамичных и наукоемких отраслей агропромышленного комплекса $[3,18,22]$. За последние годы уровень мяса птицы в мясном балансе стран мира достиг более $33 \%$, в РФ - $36 \%$. За последний период ежегодный прирост мяса птицы составляет около $10 \%[4,15,19,21]$.

Увеличение продуктивности птицы и поддержание достигнутых показателей на высоком уровне имеет большое значение. Однако с ростом продуктивности птицы становится все труднее поддерживать технологию кормления на уровне, необходимом для поддержания высокой продуктивности $[5,8,23]$.

В последнее время селен, как кормовая добавка, все больше привлекает внимание научных и практических работников как биотический элемент, который в малых количествах выполняет важные функции. Это жизненно важный микроэлемент с уникальными биологическими функциями и широ- ким спектром биологического действия его соединений $[2,9,17]$.

Большинство кормов, используемых в птицеводстве, не обеспечивает потребность птицы в селене $[7,17,20]$. Биологические свойства добавки «Ветосел Е форте» обусловлены наличием селена, который принимает участие в метаболических процессах, обладает иммуностимулирующими свойствами, оказывает на организм комплексное общеукрепляющие и антистрессовое действие, а также способствует повышению усвояемости кормов и увеличению продуктивности. В связи с этим использование кормовой добавки «Ветосел Е форте» для гусей родительского стада и гусят-бройлеров вызывает практический интерес и является актуальным.

Анализ литературных источников. Увеличение продуктивности птицы и поддержание достигнутых показателей на высоком уровне имеет большое значение. Современные рационы представляют собой концентрированные корма, обеспечивающие эффективное использование питательных веществ. Однако с ростом продуктивности птицы становится все труднее поддерживать технологию ее содержания и кормления на уровне, необходимом для поддержания высокой продуктивности $[5,8,23]$.

Селен, благодаря высокой химической активности способен образовывать сложные органические соединения, участвующие во всех биохимических процессах живого организма [2, 9, 17]. Дефицит данного элемента в рационе птицы вызывает ряд заболеваний, которые наносят существенный экономический ущерб птицеводству. Зачастую рацион сельскохозяйственной птицы не всегда удовлетворяет их потребность в селене [7, $16,20]$.

Необходимость производства комбикормов для птицы с добавками селена очевидна. Микродобавки солей селена в рацион цыплят, утят, гусят, кур-несушек, перепелок стимулируют рост и развитие, улучшают оплодотворяемость яиц, 
выводимость, повышают резистентность к болезням, увеличивают яйценоскость $[16,17]$.

Целью работы является изучение продуктивности гусей родительского стада при использовании кормовой добавки «Ветосел Е форте».

В задачи исследований входило:

- оценить уровень сохранности гусей родительского стада при использовании кормовой добавки «Ветосел Е форте»;

- определить влияние использования кормовой добавки «Ветосел Е форте» на яичную продуктивность и качество инкубационных яиц гусынь;

- установить морфобиохимические показатели крови и уровень естественной резистентности гусей родительского стада и полученных суточных гусят;

- рассчитать экономические показатели использования кормовой добавки «Ветосел Е форте» для гусей родительского стада.

Материал и методика исследования. Исследования выполнены на базе ООО «НПО «Сад и огород - Курганский гусь - Сафакулево» в соответствии с тематикой ФГБОУ ВО «Курганская государственная сельскохозяйственная академия имени Т. С. Мальцева» (№ гос. регистрации 01201151991) на гусях родительского стада итальянской белой породы. Для научнохозяйственных опытов формировали группы птицы методом сбалансированных групп, с учетом возраста, пола, живой массы, физиологического состояния.

«Ветосел Е форте» («Vetosel E forte») - кормовая добавка для обогащения и балансирования рационов сельскохозяйственных животных, в том числе птиц витамином Е и селеном. В 1 л кормовой добавки содержится в качестве действующих веществ: витамина $\mathrm{E}-68$ г, селена 2,4 г, а также вспомогательные компоненты и вода очищенная - до 1 л. Смешивание кормовой добавки с водой проводилось многоступенчато в резервуарах на 750 л. Объем выпиваемой воды составлял 3,75 г воды на 1 г потребленного гу- сями корма. При дозировке кормовой добавки 0,4 мл/10 л питьевой воды в 1 л воды содержалось витамина Е 27,20 мг и селена 0,95 мг; 0,5 мл/10 л - 34 и 1,20; 0,6 мл/10 л - 40,80 и 1,45 мг соответственно.

Научно-хозяйственный опыт на гусях родительского стада итальянской белой породы третьего года использования провели в течение продуктивного периода.

Для опыта гусей распределили в четыре группы по 1500 голов в каждой группе. Для гусей контрольной группы использовали комбикорм ПК-30; 1-й опытной - комбикорм, с добавкой «Ветосел Е форте» в дозе 0,4 мл/10 л питьевой воды; 2-й опытной - 0,5 мл/10 л; 3 опытной - 0,6 мл/10 л. Кормление гусей родительского стада проводили с учетом норм ВНИТИП [14].

Условия содержания, плотность посадки, фронт кормления и поения, параметры микроклимата во всех группах были одинаковые. При проведении экспериментов были использованы зоотехнические, гематологические, экономические и статистические методы исследований.

Количество снесенных гусынями яиц учитывалось ежесуточно, с выявлением пригодных яиц для инкубации, их визуальной оценкой и овоскопированием. Биологический контроль провели в процессе инкубации с целью определения качества яиц, контроля за эмбриональным развитием птицы, анализа результатов инкубации и оценки выведенного молодняка - по методикам ВНИТИП [6]. Морфологические, физикохимические и биохимические показатели яиц оценивали путем выборочной контрольной пробы из партии яиц - по методикам, описанным ВАСХНИЛ [1] и ВНИТИП [10].

Сохранность поголовья определяли учетом падежа гусей за весь период эксплуатации птицы. Контроль за полноценностью кормления и состоянием здоровья птицы был осуществлен путем изучения состава крови у гусынь родительского стада [12].

\section{1. Схема проведения научно-хозяйственного опыта}

\begin{tabular}{|l|c|l|}
\hline \multicolumn{1}{|c|}{ Группа } & Голов в группе & \multicolumn{1}{|c|}{ Особенности кормления } \\
\hline Контрольная & 1500 & Полнорационный комбикорм (ПК) \\
\hline 1 опытная & 1500 & $\begin{array}{l}\text { ПК, содержащий «Ветосел Е форте» в дозе } 0,4 \text { мл/10 л } \\
\text { питьевой воды }\end{array}$ \\
\hline 2 опытная & 1500 & $\begin{array}{l}\text { ПК, содержащий «Ветосел Е форте» в дозе } 0,5 \text { мл/10 л } \\
\text { питьевой воды }\end{array}$ \\
\hline 3 опытная & 1500 & $\begin{array}{l}\text { ПК, содержащий «Ветосел Е форте» в дозе } 0,6 \text { мл/10 л } \\
\text { питьевой воды }\end{array}$ \\
\hline
\end{tabular}


Экономические показатели рассчитывали на основе результатов экспериментов, себестоимости и затрат кормов, данных по продуктивности гусей [11]. Полученный цифровой материал обработан методами вариационной статистики. Разницу считали достоверной при $\mathrm{P}<0,05$ [13].

Результаты исследования. Кормление родительского стада гусей осуществляли комбикормом ПК-30, состоящим из: пшеницы 59,5\%; жмыха подсолнечного - 20,0; шрота соевого 11,1 ; БВМК Д4775 - 7,5; известняковой муки 1,7 ; соли поваренной 0,2 . Уровень концентрации обменной энергии в комбикорме составлял 263 ккал; уровень сырого протеина - 20,2 \%; сырой клетчатки - 6,7; линолевой кислоты - 2,9; кальция - 1,6; общего фосфора - 0,7; натрия - 0,3 \%.

Сохранность гусей родительского стада за продуктивный период в опытных группах была больше, в сравнении с контролем: в 1-й опытной на $0,5 \%$, во 2-й опытной - на 1,0 , в 3-й опытной - на $1,7 \%$.

Продуктивность гусынь родительского стада представлена в таблице 2 .

От гусынь опытных групп было получено за период яйценоскости больше яиц, в сравнении с контрольной: в 1-й опытной на 2,2 \%, во 2-й опытной - на 3,6, в 3-й опытной - на 10,4 \%; ва- ловой сбор яиц - соответственно на 2,2, 3,8 и 11,2 \%. Интенсивность яйценоскости практически не отличалась у гусынь всех групп, разница между максимальным и минимальным показателем составила 2,0 \%. В тоже время пик яйценоскости у гусынь контрольной, 1-й и 2-й групп в среднем составил $31,0 \%$, что меньше в сравнении с 3-й опытной на 2,5\%. Следовательно, использование кормовой добавки «Ветосел Е форте» положительно влияло на сохранность, а продуктивность была больше у гусынь, в питьевую воду которых добавляли кормовую добавку в дозе 0,6 мл/10 л питьевой воды.

Качество гусиных инкубационных яиц приведено в таблице 3. Масса яиц у гусынь, потреблявших кормовую добавку «Ветосел Е форте», была больше в сравнении с контрольной: в 1-й опытной на $0,5 \%$, во 2-й опытной - на 1,2, в 3-й опытной - на $3,1 \%(\mathrm{P} \leq 0,05)$. Плотность и объем яиц, толщина скорлупы, единицы Хау у гусынь всех групп значительно не отличалась. Разница по индексу формы также была незначительна, в среднем данный показатель у всех групп составил 69,0\%. Использование кормовой добавки «Ветосел Е форте» способствовало увеличению белка яиц опытных групп по сравнению с контрольной на 1,5, 2,1 и 4,2 \% соответственно.

\section{2. Показатели продуктивности гусынь}

\begin{tabular}{|l|c|c|c|c|}
\hline \multirow{2}{*}{\multicolumn{1}{|c|}{ Показатель }} & \multicolumn{4}{c|}{ Группа } \\
\cline { 2 - 5 } & контрольная & 1-я опытная & 2-я опытная & 3-я опытная \\
\hline Среднее поголовье гусынь, гол. & 1455 & 1456 & 1459 & 1468 \\
\hline $\begin{array}{l}\text { Яйценоскость на среднюю } \\
\text { несушку, шт. }\end{array}$ & 27,97 & 28,57 & 28,98 & 30,88 \\
\hline Валовой сбор яиц, тыс. штук & 40,73 & 41,61 & 42,28 & 45,28 \\
\hline Интенсивность яйценоскости, \% & 90,52 & 89,03 & 89,93 & 90,99 \\
\hline Пик яйценоскости, \% & 30,42 & 31,07 & 31,50 & 33,52 \\
\hline
\end{tabular}

\section{3. Результаты оценки качества яиц в середине яйценоскости $(\overline{\mathrm{X}} \pm \mathrm{S} \overline{\mathrm{x}})$}

\begin{tabular}{|l|c|c|c|c|}
\hline \multirow{2}{*}{\multicolumn{1}{|c|}{ Показатель }} & \multicolumn{4}{c|}{ Группа } \\
\cline { 2 - 5 } & контрольная & 1 -я опытная & 2-я опытная & 3-я опытная \\
\hline Масса яйца, г & $146,70 \pm 0,72$ & $147,37 \pm 1,14$ & $148,47 \pm 1,27$ & $151,23 \pm 0,73 *$ \\
\hline Плотность яйца, г/см ${ }^{3}$ & $1,081 \pm 0,004$ & $1,083 \pm 0,001$ & $1,082 \pm 0,001$ & $1,083 \pm 0,006$ \\
\hline Объем яйца, см ${ }^{3}$ & $135,67 \pm 0,31$ & $136,07 \pm 0,97$ & $137,25 \pm 1,20$ & $139,70 \pm 0,32$ \\
\hline Индекс формы яйца, \% & $69,27 \pm 2,69$ & $69,01 \pm 2,31$ & $69,26 \pm 2,25$ & $68,39 \pm 1,38$ \\
\hline Толщина скорлупы, мм & $0,502 \pm 0,007$ & $0,504 \pm 0,008$ & $0,506 \pm 0,003$ & $0,506 \pm 0,003$ \\
\hline Единица Хау & $79,87 \pm 1,88$ & $80,53 \pm 0,52$ & $80,39 \pm 2,84$ & $80,75 \pm 0,37$ \\
\hline $\begin{array}{l}\text { Отношение массы } \\
\text { белка к массе желтка }\end{array}$ & $1,84 \pm 0,27$ & $1,83 \pm 0,12$ & $1,84 \pm 0,16$ & $1,85 \pm 0,06$ \\
\hline
\end{tabular}

Здесь и далее *P $\leq 0,05 * * \mathrm{P} \leq 0,01 * * * \mathrm{P} \leq 0,001$ 


\section{СІЛЬСЬКЕ ГОСПОДАРСТВО. ТВАРИННИЦТВО}

Увеличение массы скорлупы в опытных группах по сравнению с контролем составило: в 1-й опытной на $0,1 \%$, во 2-й опытной - на 1,6 , и в 3 -й опытной - на 5,3\%. Таким образом, использование кормовой добавки «Ветосел Е форте» не оказало значительного влияния на качество яиц, за исключением достоверного $(\mathrm{P} \leq 0,05)$ увеличения массы яиц у гусынь 3 опытной группы, потреблявших используемый препарат в дозе 0,6 мл/10 л питьевой воды, что в свою очередь отразилось на массе белка и скорлупы.

Анализ результатов инкубации представлен в таблице 4.

Установлено, что оплодотворенность яиц во 2-й и 3-й опытных группах была больше, чем в контроле на 2,5 и 3,1\% соответственно. Выводимость в опытных группах была больше, чем в контрольной на 5,8, 7,6 и 11,0 \%, а вывод - на $6,1,8,9$ и $12,7 \%$ соответственно. От гусынь опытных групп было получено больше кондиционного молодняка, чем в контрольной на 10,5, 13,9 и 19,5 \% соответственно. Таким образом, увеличение дозировки кормовой добавки «Ветосел Е форте» с 0,5 мл/10 л до 0,6 мл/10 л питьевой воды способствовало увеличению жизнеспособности эмбрионов и получению кондиционного молодняка.

Гематологические показатели гусей и суточных гусят. Использование кормовой добавки «Ветосел Е форте» в составе питьевой воды для гусей не оказало отрицательного влияния на гематологические показатели. При использовании добавки в дозе 0,6 мл/10 л в середине яйценоскости отмечалось более интенсивно выраженное тканевое дыхание (цветной показатель больше, чем в контроле на 14,6 \%, 1-й опытной - на 14,1 и 2-й опытной - на 9,0\%). Уменьшение содержания кальция (на 3,9\%) и общего белка (на 15,9 \%) связано с большей продуктивностью гусей, однако отклонений от физиологической нормы отмечено не было.

Клеточные факторы неспецифического иммунитета у гусей отражены в таблице 5 .

В начале периода яйценоскости фагоцитарные реакции гусынь всех групп значительно не отличались. В середине периода яйценоскости фагоцитарное число у гусей опытных групп больше по сравнению с контрольной: в 1-й опытной на $5,6 \%$, во 2-й опытной - на $14,0(\mathrm{P} \leq 0,05)$, в 3-й опытной - на $28,8 \%(\mathrm{P} \leq 0,01)$; фагоцитарный индекс - на $0,3,2,9(\mathrm{P} \leq 0,05)$ и $11,5 \%(\mathrm{P} \leq 0,01)$ соответственно. К концу яйценоскости фагоцитарная активность была больше у гусей опытных групп на 4,3, 9,0 (P $\leq 0,05)$ и $11,3 \%(\mathrm{P} \leq 0,01)$; фагоцитарное число - на $17,7,29,1 \quad(\mathrm{P} \leq 0,05)$ и $35,8 \%(\mathrm{P} \leq 0,01)$; фагоцитарный индекс - на 7,7, 8,1 и $9,5 \%(\mathrm{P} \leq 0,05)$ соответственно по сравнению с контролем. В большей степени поддержание уровня естественной резистентности наблюдалось у гусей 2-й и 3-й опытных групп, потреблявших добавку в дозировках 0,5 и 0,6 мл/10 л.

Гематологические показатели суточных гусят, полученных от гусынь родительского стада представлены в таблице 6.

Число эритроцитов у гусят всех групп значительно не отличалось, однако по содержанию гемоглобина и цветному показателю гусята 3-й опытной группы превышали контрольную на 6,1 и 5,8 \%, 1-ю опытную - на 3,6 и 2,2; 2-ю опытную - на 2,8 и $0,6 \%$ соответственно.

\section{4. Инкубационные качества яиц гусынь, \%}

\begin{tabular}{|l|c|c|c|c|}
\hline \multirow{2}{*}{\multicolumn{1}{|c|}{ Показатель }} & \multicolumn{4}{c|}{ Группа } \\
\cline { 2 - 5 } & контрольная & 1 -я опытная & 2 -я опытная & 3-я опытная \\
\hline Оплодотворенность & 92,19 & 93,18 & 94,64 & 95,28 \\
\hline Выводимость & 69,98 & 75,79 & 77,55 & 81,00 \\
\hline Вывод & 64,52 & 70,62 & 73,39 & 77,18 \\
\hline Кондиционный молодняк, гол. & 11734 & 12970 & 13363 & 14027 \\
\hline
\end{tabular}

\section{5. Фагоцичтарные реакции у гусей в середине яйценоскости ( $\overline{\mathrm{X}} \pm \mathrm{S} \overline{\mathrm{X}})$}

\begin{tabular}{|l|c|c|c|c|}
\hline \multirow{2}{*}{\multicolumn{1}{|c|}{ Показатель }} & \multicolumn{4}{c|}{ Группа } \\
\cline { 2 - 5 } & контрольная & 1 -я опытная & 2 -я опытная & 3 -я опытная \\
\hline Фагоцитарная активность, \% & $51,67 \pm 0,93$ & $54,67 \pm 1,20$ & $57,33 \pm 1,20^{*}$ & $59,67 \pm 0,88^{* *}$ \\
\hline Фагоцитарное число & $3,93 \pm 0,10$ & $4,16 \pm 0,07$ & $4,48 \pm 0,11^{*}$ & $5,06 \pm 0,12^{* *}$ \\
\hline Фагоцитарный индекс & $7,60 \pm 0,06$ & $7,62 \pm 0,03$ & $7,82 \pm 0,03 *$ & $8,47 \pm 0,10^{* *}$ \\
\hline $\begin{array}{l}\text { Фагоцитарная ёмкость, тыс. мик. } \\
\text { тел }\end{array}$ & $165,64 \pm 3,42$ & $165,12 \pm 9,91$ & $173,91 \pm 12,32 *$ & $181,22 \pm 6,55^{* *}$ \\
\hline
\end{tabular}


СІЛЬСЬКЕ ГОСПОДАРСТВО. ТВАРИННИЦТВО

6. Гематологические показатели суточных гусят ( $\overline{\mathrm{X}} \pm \mathrm{S} \overline{\mathrm{X}})$

\begin{tabular}{|l|c|c|c|c|}
\hline \multirow{2}{*}{\multicolumn{1}{|c|}{ Показатель }} & \multicolumn{4}{c|}{ Порода } \\
\cline { 2 - 5 } & контрольная & 1 -я опытная & 2-я опытная & 3-я опытная \\
\hline Эритроциты, х 10 $12 /$ л & $2,41 \pm 0,06$ & $2,40 \pm 0,02$ & $2,37 \pm 0,04$ & $2,42 \pm 0,08$ \\
\hline Гемоглобин, г/л & $123,86 \pm 9,90$ & $126,91 \pm 1,37$ & $127,87 \pm 1,79$ & $131,41 \pm 3,32$ \\
\hline Цветной показатель & $1,54 \pm 0,09$ & $1,58 \pm 0,03$ & $1,62 \pm 0,02$ & $1,63 \pm 0,08$ \\
\hline Лейкоциты, х 109/л & $24,83 \pm 2,86$ & $25,13 \pm 2,58$ & $31,03 \pm 0,74$ & $31,65 \pm 1,10$ \\
\hline Фагоцитарная активность, \% & $58,33 \pm 1,76$ & $58,67 \pm 2,91$ & $61,33 \pm 2,03$ & $62,67 \pm 1,45$ \\
\hline Фагоцитарное число & $4,96 \pm 0,13$ & $5,04 \pm 0,16$ & $5,32 \pm 0,17$ & $5,47 \pm 0,08^{*}$ \\
\hline Фагоцитарный индекс & $8,50 \pm 0,09$ & $8,61 \pm 0,18$ & $8,68 \pm 0,23$ & $8,74 \pm 0,23$ \\
\hline $\begin{array}{l}\text { Фагоцитарная емкость, } \\
\text { тыс. мик. тел }\end{array}$ & $210,67 \pm 22,27$ & $215,67 \pm 18,34$ & $275,08 \pm 11,04$ & $276,46 \pm 11,12^{*}$ \\
\hline
\end{tabular}

Фагоцитарная активность у гусят 3-й опытной группы была больше, чем в контроле на $4,3 \%$, в 1-й опытной - на 4,0 и во 2-й опытной - на $1,3 \%$. Как фагоцитарное число, так и индекс у гусят 3 опытной группы были больше по сравнению с контролем на $10,3(\mathrm{P} \leq 0,05)$ и $2,8 \%$, с 1 -й опытной - на 8,5 и 1,5; со 2-й опытной - на 2,8 и $0,7 \%$ соответственно. Следовательно, суточные гусята, полученные от гусынь, потреблявших с водой кормовую добавку «Ветосел $\mathrm{E}$ форте» в дозе 0,5 мл/10 л и 0,6 мл/ 10 л питьевой воды, отличались более высоким неспецифическим иммунитетом.

Эффективность использования кормовой добавки «Ветосел Е форте» при производстве инкубационных яиц показана в таблице 7.

Валовой сбор яиц был больше в опытных группах в сравнении с контрольной соответственно: в 1-й опытной на $2,2 \%$, во 2-й опытной на 3,8 , в 3 -й опытной - на $11,2 \%$. Выход инкубационного яйца увеличился в опытных группах на 0,9-2,3 \% по сравнению с контролем. Расход комбикорма за весь период эксплуатации птицы и на 1 голову между группами различался незначительно, а расход комбикорма на производство 1000 штук яиц, был меньше в опытных группах на 2,3, 6,5 и $12,8 \%$ соответственно, чем в контроле. От гусей опытных групп было реализовано больше инкубационного яйца по сравнению с контролем на 3,1, 5,7 и 13,9\% соответственно. Рентабельность производства инкубационного яйца была больше в опытных группах по сравнению с контролем на 1,98, 4,09 и 4,74 \% соответственно. Следовательно, более эффективной при производстве гусиных инкубационных яиц оказалась дозировка 0,6 мл/10 л кормовой добавки «Ветосел Е форте».

\section{Выводы:}

1. Яичная продуктивность (на $2,15-10,40 \%$ ) и сохранность (на 0,47-1,68 \%) была больше у гусей родительского стада, потреблявших кормовую добавку «Ветосел Е форте». Гусыни опытных групп отличались от контроля большей оплодотворенностью яиц на 0,99-3,09 \%, выводимостью - на 5,81-11,02 и выводом - на 6,10$12,66 \%$.

\section{7. Экономические показатели использования добавки «Ветосел Е форте» при производстве} инкубационных яиц

\begin{tabular}{|l|c|c|c|c|}
\hline \multirow{2}{*}{\multicolumn{1}{|c|}{ Показатель }} & \multicolumn{4}{c|}{ Группа } \\
\cline { 2 - 5 } & контрольная & 1 -я опытная & 2-я опытная & 3-я опытная \\
\hline Валовой сбор яиц, тыс. шт. & 40,73 & 41,61 & 42,28 & 45,28 \\
\hline Выход инкубационного яйца, \% & 95,90 & 96,78 & 97,63 & 98,23 \\
\hline $\begin{array}{l}\text { Расход комбикорма } \\
\text { за период эксплуатации, т }\end{array}$ & 44,39 & 44,73 & 43,86 & 44,06 \\
\hline $\begin{array}{l}\text { Расход комбикорма } \\
\text { на 1000 шт. яиц, кг }\end{array}$ & 1136,46 & 1110,75 & 1062,55 & 990,59 \\
\hline $\begin{array}{l}\text { Реализовано инкубационного } \\
\text { яйца, тыс. шт. }\end{array}$ & 39,06 & 40,27 & 41,28 & 44,48 \\
\hline $\begin{array}{l}\text { Себестоимость 1000 шт. } \\
\text { инкубационных яиц, тыс. р. }\end{array}$ & 60,66 & 60,13 & 59,55 & 59,58 \\
\hline Рентабельность, \% & 10,67 & 12,66 & 14,77 & 15,42 \\
\hline
\end{tabular}




\section{СІЛЬСЬКЕ ГОСПОДАРСТВО. ТВАРИННИЦТВО}

2. Использование кормовой добавки не оказало значительного влияния на качество яиц, однако, увеличение дозировки способствовало повышению жизнеспособности эмбрионов и получению большего числа кондиционного молодняка на 10,53-19,54\%.

3. Кормовая добавка «Ветосел Е форте» в составе питьевой воды не оказала отрицательного влияния на гематологические показатели гусей. При применении дозировки 0,6 мл/10 л отмечалось более интенсивно выраженное тканевое дыхание, уменьшение содержания кальция и общего белка, что связано с большей продуктивностью гусей, однако выхода показателей за пределы физиологической нормы отмечено не было.

4. В большей степени сохранение уровня естественной резистентности наблюдалось у гусей,

\section{БИБЛИОГРАФИЯ}

1. Агеева Л. Н. Методические рекомендации по проведению исследований технологии производства мяса птицы / Л. Н. Агеева [и др.]. - М. : ВАСХНИЛ, 1981. - 50 с.

2. Бакаева Л. Н. Химический состав и биологическая ценность мяса цыплят-бройлеров при применении селеносодержащей кормовой добавки / [Бакаева Л. Н., Топурия Г. М., Топурия Л. Ю. и др.] // Вестник АПК Ставрополья. 2015. - №5-1. - С. 189-192.

3. Бобылев $Г$. А. Российское птицеводство: анализ, тенденции, прогнозы / Г. А. Бобылев // Птица и птицепродукты. - 2010. - №3. - С. 1216.

4. Бобылева Г. А., Радкевич В. С. Птицеводство России: целевая программа развития до 2015 года / Г.А. Бобылева, В.С. Радкевич // Птица и птицепродукты. - 2013. - №1. - С. 4-6.

5. Гражданкин Б. Технический семинар по птицеводству / Б. Гражданкин // Комбикорма. 2013. - №12. - С. 87-88.

6. Дядичкина Л. Ф. Руководство по биологическому контролю при инкубации яиц сельскохозяйственной птицы: методические рекомендации / Дядичкина Л. Ф. [и др.]. - Сергиев Посад, 2006. $-83 \mathrm{c}$.

7. Забашта Н. Н. Селен в составе органической кормовой добавки для цыплят / Забашта Н.Н. [и др.] // Сборник научных трудов СевероКавказского научно-исследовательского института животноводства. - 2015. - Т.4. - С. 44-52.

8. Исаев P. A. Птицеводство Дагестана - на новый уровень развития / Р. А. Исаев // Современные проблемы науки и образования. - 2014. - №3. - С. 324. потреблявших добавку «Ветосел Е форте» в дозировках 0,5 и 0,6 мл/10 л. Фагоцитарная активность, число и индекс были в среднем больше на $4,34 \%, 10,28(\mathrm{P} \leq 0,05)$ и 2,82 \%. Суточные гусята, полученные от этих гусынь, также отличались более высоким неспецифическим иммунитетом.

5. При использовании кормовой добавки «Ветосел Е форте» расход корма на 1000 шт. яиц уменьшился на 2,26-12,84\%, а уровень рентабельности производства инкубационных гусиных яиц увеличился на 1,98-4,74 \%.

Исходя из полученных в ходе исследования результатов, рекомендуем гусям родительского стада для увеличения сохранности, продуктивных показателей и жизнеспособности полученного молодняка использовать кормовую добавку «Ветосел Е форте» в дозировке 0,6 мл/10 л питьевой воды.

9. Карпеня М. М. Экономическая эффективность применения органического селена в кормлении ремонтных бычков / [Карпеня М. М., Шамич Ю. В., Карпеня С. Л., Подрез В. Н., Дуброва Ю. Н.] // Ученые записки учреждения образования «Витебская ордена «Знак почета» государственная академия ветеринарной медицины». - 2012. - T. 48. - №1. - C. 238-241.

10. Лукашенко B. C. Методические рекомендации по проведению анатомической разделки тушек и органолептической оценки качества мяса и яиц сельскохозяйственной птицы и морфологии яиц / В. С. Лукашенко [и др.]. - Сергиев Посад : ВНИТИП, 2001. - 27 с.

11. Методика определения экономической эффективности использования в сельском хозяйстве результатов научно-исследовательских и опытно-конструкторских работ, новой техники, изобретений и рационализаторских предложений. - М. : Колос, 1980. - 112 с.

12. Осипова Н. А. Лабораторные исследования крови животных / Н. А. Осипова, С. Н. Магер, Ю. Г. Попов. - Новосибирск, 2003. - 48 с.

13. Плохинский Н. А. Руководство по биометрии для зоотехников / Н. А. Плохинский. - М. : Колос, 1969. - 256 с.

14. Промышленное птицеводство / [под ред. В. И. Фисинина]. - Сергиев Посад : ГНУ ВНИТИП Россельхозакадемии, 2010. - 600 с.

15. Птицеводство России // Комбикорма. 2014. - №10. - С. 6-14.

16. Суханова С. Ф., Махалов А. Г. Энергетический обмен и конверсия питательных веществ в организме молодняка гусей, потреблявшего различные формы селена / С. Ф. Суханова, 
А.Г. Махалов // Аграрный вестник Урала. 2010. - №7 (73). - С. 41-42.

17. Суханова C. Эффективность использования комбикормов с добавлением селена гусыням родительского стада / С. Суханова, А. Махалов, Н. Торопова // Птицеводческое хозяйство/птицефабрика. - 2011. - №11. - С. 15-17.

18. Суханова С. Ф., Азаубаева Г. С. Научное и практическое обоснование эффективности использования кормовых средств в гусеводстве / С. Ф. Суханова, Г. С. Азаубаева. - Курган : издво КГСХА, 2015. - 472 с.

19. Тарасова Н. В., Чернякевич Л. М. Тенденции развития птицеводства в трансформационной экономике / Н. В. Тарасова, Л. М. Чернякевич // Современные проблемы науки и образова- ния. - 2013. - №4. - С. 259.

20. Тэйлор-Пикард Д. Органический селен повышает качество мяса птицы / Д. Тэйлор-Пикард // Комбикорма. - 2015. - №7-8. - С. 71-72.

21. Фисинин В. И. Интересы отрасли - под защитой Росптицесоюза / В. И. Фисинин // Птицеводство. - 2009. - №2. - С. 2-3.

22. Фисинин В. И., Егоров И. А. Современные подходы к кормлению высокопродуктивной птицы / В. И. Фисинин, И. А. Егоров // Птица и птицепродукты. - 2015. - №3. - С. 27-29.

23. Hetland $H$. Effects of oat hulls and wood shavings on digestion in broilers and layers fed diets based on whole or ground wheat / H. Hetland, B. Svihus, A. Krogdahl // Brit. Poulry Sci. - 2003. V. 44. - P. 275-282. 